\title{
PHYSICIAN APPRAISALS: KEY CHALLENGES
}

\begin{abstract}
A B S T R A C T
The main purpose of the article is to identify key criteria being used for physician appraisals and to find how communication skills of physicians are valued in those appraisals. ScienceDirect and EBSCOhost databases were used for this search. The results show that a physician appraisal is underestimated both theoretically and empirically. The particular gap exists with respect to the communication skills of physicians, which are rarely present in medical training syllabi and physician assessments. The article contributes to the theoretical discourse on physician appraisals and points out at the inconsistency between the high status of physicians as a key hospital resource on the one hand and, on the other hand, at inadequate and poorly researched assessment of their performance with a special emphasis on communication skills. The article may inspire health managers to develop and implement up-to-date assessment forms for physicians and good managerial practices in this respect in hospitals and other health care units.
\end{abstract}

KEY WORDS

physician appraisal, physician assessment, communication skills

DOI: 10.1515/emj-2017-0012
Corresponding author:

Jacek Klich

$$
\begin{array}{r}
\text { Cracow University of Economics, } \\
\text { Faculty of Public Economy and } \\
\text { Administration, } \\
\text { Department of Public Economy and } \\
\text { Administration, Poland } \\
\text { e-mail: uuklich@cyf-kr.edu.pl }
\end{array}
$$

\section{INTRODUCTION}

This paper originated from both theory and practice. The theoretical aspect was connected with a paper recently published by Schumacher et al. (2016), which concluded that the assessment of physician performance across the continuum of training and practice in the USA was inadequate. Considering that when it comes to employed physicians, employee performance evaluations are often an exception rather than the norm (Jessee, 2016) just these two assessments speak for further inquiry into physician appraisals. The practical aspect appeared in discussions with physicians during the author's lectures on management of health care units within the framework of postgraduate studies on management in the healthcare sector in the Collegium Medicum, Jagiel- 
lonian University, Cracow, Poland. The students pointed out having rather weak communication skills especially (but not exclusively) while in contact with patients. Such a negative self-assessment of Polish physicians may give rise to a concern since in the United States, the Accreditation Council for Graduate Medical Education (ACGME) and the American Board of Medical Specialties (ABMS) jointly identified interpersonal and communication skills as one of the six general competencies for physicians (Batalden et al., 2002; Horowitz, 2000). Consequently, the aim of the paper is to answer two broad research questions: what are the basic elements of a physician performance evaluation? and how a physician's communication skills are weighted?

\section{LITERATURE REVIEW}

Having in mind that this is a review article, the literature overview constitutes its core element and is presented under 3. Research results below. Here, just one finding should be mentioned. It says that not only physician assessment but the whole human resource management in the health sector is weak (Kanellopoulos, 2012). This, in turn, raises further questions regarding the causes for this, keeping in mind that employees in the health care sector in general and physicians, in particular, are perceived as the most precious assets and/or key success factors of hospitals and other health care providers. Such a statement further legitimises physician appraisals as the research topic. An appraisal is defined here as a process to provide feedback on the performance of doctors, chart their continuing professional development, and identify their developmental needs (Appraisal for Doctors in Hospital Practice, 2006, p. 2).

\section{RESEARCH METHODS}

This review article is based upon the contents of two databases: ScienceDirect and EBCSOhost. The following keywords were used for search (in various combinations): physicians, appraisal, assessment, performance, communication skills, and peer assessment. The search was narrowed down to title, abstract and keywords. With a few exceptions, the period for the search was narrowed to 2006-2016. The two-step selection process was used. In the first stage, records were assessed based on the correspondence to the topic and appropriateness. In the result, 274 records were identified. In the second stage, all abstracts were read. Finally, based on the content of abstracts, 42 articles were found to meet the inclusion criteria and were analysed in-depth.

\section{RESEARCH RESULTS AND DISCUSSION}

Although topics connected with managing physicians are represented in the literature (maybe in slightly less extent than, for example, management of nurses), the more specific issues about physician assessment and appraisal are comparatively less represented. While most organisations conduct employee performance evaluations at least annually, and, generally, use a standard evaluation tool, in hospitals, evaluations of employed physicians are rare, and evaluation tools differ considerably (Jessee, 2016).

Parallelly, one may observe an increased emphasis on the individual performance of doctors in improving the quality of healthcare (Klass, 2007). Here, medical competences of physicians take the lead followed by their performance. Competence in medicine is understood as the habitual and judicious use of communication, knowledge, technical skills, clinical reasoning, emotions, values, and reflection in daily practice for the benefit of the individuals and communities being served.

\subsection{Elements of A PHYSiCian ASSESSMENT}

Epstein and Hundert identified seven dimensions of professional competence of a physician: $\operatorname{cog}$ nitive, technical, integrative, context, relationship, affective/moral, and habits of mind (Epstein \& Hundert, 2002, p. 227). Within the framework of relationship the following categories were identified: communication skills, handling conflict, teamwork, teaching others: patients, students, and colleagues (Epstein \& Hundert, 2002, p. 227).

In the United States, the assessment of medical residents and increasingly medical students is largely based on a model that was developed by ACGME. This model uses six interrelated domains of competence: medical knowledge, patient care, professionalism, communication and interpersonal skills, practice-based learning and improvement, and systems-based practice (Batalden et al., 2002). Klass 
(2007) distinguishes between four main frames of assessment of a physician competence:

- assessments undertaken before actual practice (achievement tests and simulations, including practice under supervision, which permit evaluators to predict future competence of a trainee),

- competence in practice from participation in continuing medical education and training programs or related achievement tests, measures that examine work processes of a physician (peer reviews of medical records, surveys of co-workers and colleagues about a physician's communication skills and collaborative practices),

- assessments that use standardised patient data, diaries, or portfolios to add contextual detail about work activities,

- assessments of the outcomes of a doctor's work, including patient satisfaction surveys, complaints or malpractice claims, specific markers of patient outcomes or wellness, and data on mortality and morbidity.

Addressing the issue of principles applicable to the assessment of physicians and answering the question what to assess, Epstein (2007) pointed out eight measures: habits of mind and behaviour, acquisition and application of knowledge and skills, communication, professionalism, clinical reasoning and judgment in uncertain situations, teamwork, practice-based learning and improvement, and systems-based practice (Epstein, 2007, p. 394).

Among the most common measures of physician performance, clinical skills get the lead. Jessee (2016) identified here nine measures: patient relationships, peer and colleague relationships, support staff relationships, patient recordkeeping, patient compliance, sensitivity to patient language and cultural differences, behaviour, citizenship, and support for quality improvement initiatives.

Other authors proposed an extensive list of various methods and tools of physician assessment including: simulated patients, video observation, direct observation, peer assessment, audit of medical records, portfolio or appraisal (Marjan et al., 2007), practice audits, practice visits (Contencin et al., 2006), case-based discussion, assessment of clinical expertise, mini-assessed clinical encounter, mini peer assessment tool, direct observations of procedural skills, patient satisfaction questionnaires, case conference, and journal club presentation (Brittlebank et al., 2013). Peer assessment and feedback are an important part of professional development (Sargeant et al., 2013), and peer-assessment tools are used during various stages of careers of health professionals (Lull et al., 2016), by different specialists (Violato \& Lockyer, 2006; Sasaki et al., 2015; Teter et al., 2016; Kemper et al., 2014), and/or in respect to different treatments (O'Shaughnessy \& Joyce, 2015; Bender et al., 2009). It is worth to notice, however, that the instruments developed for physicians to evaluate characteristics of colleagues need further improvement (Evans et al., 2004).

The importance of organisational and cultural differences notwithstanding, one may maintain, that some already existing tools like communication assessment tools (CAT) can be used by various health care providers (Stausmire et al., 2015), and some of the peer-review tools, for example, SPRAT (Sheffield peer-review assessment tool) proved to be useful internationally as well (Sasaki et al., 2015).

In their systematic review, Overeem et al. (2007) identified six different methods of evaluating the performance of an individual physician: simulated patients, video observation, direct observation, peer assessment, an audit of medical records, and portfolio or appraisal. They conclude that little psychometric assessment of the instruments has been undertaken so far and effectiveness of formative assessments is poorly studied. The fact that all six systems but two rely on a single method to assess performance indicates that there is considerable room for improvement in the process of a physician appraisal.

There are recommendations available in the literature. Epstein proposed seven hints regarding the assessment process:

- use multiple methods and a variety of environments and contexts to capture different aspects of performance,

- organise assessments into repeated, ongoing, contextual, and developmental programs,

- balance the use of complex, ambiguous real-life situations requiring reasoning and judgment with structured, simplified, and focused assessments of knowledge, skills, and behaviour,

- include directly observed behaviour,

- use experts to test expert judgment,

- use pass-fail standards that reflect appropriate developmental levels,

- provide timely feedback and mentoring (Epstein, 2007, p. 394).

\subsection{COMMUNICATION SKILLS OF A PHYSICIAN}

As indicated earlier, communication skills are perceived as an important domain of competence for 
physicians. Effective communication is broadly acknowledged as critical to patient satisfaction, outcomes of care and malpractice prevention (Newcomb et al., 2016). Although good communication skills are required from any physician, surgeons need particularly effective communication skills to discuss complicated procedures and help patients make informed choices, which goes far beyond patient satisfaction. Consequently, communication skills of physicians, especially at the beginning of their professional career, get increasing attention in the literature (Taveira-Gomes et al., 2016; Newcomb et al., 2016; Liu et al., 2015). As indicated in the literature, there is a positive association between communication skills of a physician, self-efficacy and performance (Gulbrandsen et al., 2013), which reinforces the necessity to develop communication skills among physicians.

The overall assessment of effective communication skills among physicians is not positive, and the lack of communication skills is diagnosed (Haglund et al., 2015). It is explained by a limited in time training in communication skills, which is not integrated into the curriculum and scarcely contextualised (Deveugele, 2015). It is significant that the evidence on communication skills training is scarce or contradictory (Deveugele, 2015) despite a wide acknowledgement of their importance and weight. Even when surgeons spend the majority of their time educating patients and helping them to make choices providing details about surgical conditions and treatments, they often do not explore emotions or concerns of patients (Levinson et al., 2013). Young physicians seem to value communication skills but very often they are not provided with formal training in this respect (Haglund et al., 2015), which contradicts other findings, such as high appreciation of communication tailored to patients (Mazzi et al., 2015), which, in turn, requires considerable communication skills from physicians.

\section{DISCUSSION OF THE RESULTS}

Strong empirical results of the research on physician appraisal with a special emphasis on communication skills are scarce. For example, Levinson et al. (2013) got 2794 citations and 74 full-text articles, 21 studies and 13 companion reports; Liu et al. (2015) retrieved 20 studies; Mazzi et al. (2013) reported on one full-day observation with 259 people (but only four interviews were analysed); Taveira-Gomes et al. (2016) researched on 255 students attending the course on basic communication skills but then after three years - only 68 people from the same population completed the re-evaluation interview. Stausmire et al. (2015) researched 93 residents (representing 59 institutions) participating in the communication training but finally only 11 of them volunteered to participate in a role-playing session before and after the formal teaching session. This leads to the statement that research on communication skills of physicians is in its initial stage and should be intensified.

\section{CONCLUSIONS}

Based on the above, one may conclude that:

- physician appraisals are underestimated both theoretically and empirically despite their objective high importance and weight,

- often assessment tools and instruments in use (especially in peer assessment) lack reliability and validity testing,

- peer-review constitutes a valuable and useful tool for physician appraisals,

- despite the acknowledged (and proved) importance of physician communication skills, this area leaves considerable room for improvement. There are several challenges faced by health care managers and physicians, to mention just two:

- there is a need to address training around the management of performance issues to improve the experience for both the appraiser and the appraisee (Cohen \& Rhydderch, 2010),

- the shared interprofessional learning model seems promising as an effective method for developing person-centred communication skills but must be further developed (Cavanaugh \& Konrad, 2012).

There are many questions which still remain unanswered but should be addressed by researchers, for example:

- How to assess interprofessional teamwork (Chesluk et al., 2015)?

- How to use Electronic Medical Records (EMR) for better assessment?

- How to measure communication skills of physicians in an online environment?

All the above proves that appraisal of physicians in general and their communication skills in particu- 
lar constitute an attractive and largely unexplored field of research.

\section{ACKNOWLEDGEMENTS}

This article has been developed within the framework of research Human Capital Management in Hospitals, which is financed thanks to the resources of the Polish National Science Centre (NCN) on the basis of Decision No. DEC2013/11/B/HS4/01062.

\section{LITERATURE}

Abdulla, A. (2008). A critical analysis of mini peer assessment tool (mini-PAT). Journal of The Royal Society of Medicine, 101(1), 22-6.

Batalden, P., Leach, D., Swing, S., Dreyfus, H., \& Dreyfus, S. (2002). General competencies and accreditation in graduate medical education. Health Affairs, 21(5), 103-111.

Bender, L. C., Klingensmith, M. E., Freeman, B. D., Chapman, W. C., Dunagan, W. C., Gottlieb, J. E., \& Hall, B. L. (2009). Anonymous group peer review in surgery morbidity and mortality conference. The American Journal of Surgery, 198(2), 270-276.

Brittlebank, A., Archer, J., \& Longson, D. (2013). Workplace-Based Assessments in Psychiatry: Evaluation of a Whole Assessment System. Academic Psychiatry, 37(5), 301-307.

Cavanaugh, J., \& Konrad, S. C. (2012). Fostering the development of effective person-centered healthcare communication skills: An interprofessional shared learning model. Work, 41(3), 293-301.

Chesluk, B. J., Reddy, S., Hess, B., Bernabeo, E., Lynn, L., \& Holmboe, E. (2015). Assessing Interprofessional Teamwork: Pilot Test of a New Assessment Module for Practicing Physicians. Journal of Continuing Education in the Health Professions, 35(1), 3-10.

Cohen, D., \& Rhydderch, M. (2010). Making an objective assessment of a colleague's performance. Clinical Teacher, 7(3), 171-174.

Contencin, P., Falcoff, H., \& Doumenc, M. (2006). Review of performance assessment and improvement in ambulatory medical care. Health Policy, 77(1), 64-75.

Deveugele, M. (2015). Communication training: Skills and beyond. Patient Education and Counseling, 98(10), 1287-1291.

Epstein, R. M. (2007). Assessment in Medical Education. The New England Journal of Medicine, 356(4), 387396.

Epstein, R. M., \& Hundert, E. M. (2002). Defining and assessing professional competence. The Journal of the American Medical Association, 287(2), 226-235.

Evans, R., Elwyn, G., \& Edwards, A. (2004). Review of instruments for peer assessment of physicians. British Medical Journal, 328(7450), 1240-1243.
Haglund, M. M., Rudd, M., Nagler, A., \& Prose, N. S. (2015). Difficult Conversations: A National Course for Neurosurgery Residents in Physician-Patient Communication. Journal of Surgical Education, 72(3), 394-401.

Horowitz, S. D. (2000). Evaluation of clinical competencies: basic certification, subspecialty certification, and recertification. American Journal of Physical Medicine \& Rehabilitation, 79(5), 478-80.

Jessee, W. (2016). Assessing the Performance of Employed Physicians. Integrated Healthcare Strategies. Retrieved from http://www.integratedhealthcarestrategies. com/knowledgecenter_article.aspx?article_id=8633

Kanellopoulos, D. (2012). Comparative approach at the European level of the human resources management of the health system. Procedia - Social and Behavioral Sciences, 46, 5274-5279.

Kemper, M., Linke, J., Zahnert, T., \& Neudert, M. (2014). Peer teaching and peer assessment are appropriate tools in medical education in otorhinolaryngology. Laryngorhinootologie, 93(6), 392-397.

Klass, D. (2007). Assessing doctors at work -progress and challenges. The New England Journal of Medicine, 356(4), 414-415.

Levinson, W., Hudak, P., \& Tricco, A. C. (2013). A systematic review of surgeon-patient communication: Strengths and opportunities for improvement. Patient Education and Counseling, 93(1), 3-17.

Liu, X., Rohrer, W., Luo, A., Fang, Z., He, T., \& Xie, W. (2015). Doctor-patient communication skills training in mainland China: A systematic review of the literature. Patient Education and Counseling, 98(1), 3-14.

Lull, M. E., \& Mathews, J. L. (2016). Online Self-testing Resources Prepared by Peer Tutors as a Formative Assessment Tool in Pharmacology Courses. The American Journal of Pharmaceutical Education, 80(7), 1-9.

Makoul, G., Krupat, E., \& Chang, C. H. (2007). Measuring patient views of physician communication skills: Development and testing of the Communication Assessment Tool. Patient Education and Counseling, 67(3), 333-342.

Mazzi, M. A., Bensing, J., Rimondini, M., Fletcher, I., van Vliet, L., Zimmermann, C., \& Deveugele, M. (2013). How do lay people assess the quality of physicians' communicative responses to patients' emotional cues and concerns? An international multicentre study based on videotaped medical consultations. Patient Education and Counseling, 90(3), 347-353.

Newcomb, A. B., Trickey, A. W., Porrey, M., Wright, J., Piscitani, F., Graling, P., \& Dort, J. (2016). Talk the Talk: Implementing a Communication Curriculum for Surgical Residents. Journal of Surgical Education, 74(2), 319-328.

NHS Professionals. (2006). Appraisal for Doctors in Hospital Practice. A Handbook for NHS Professionals (Doctors) Appraisers and Appraisees. Retrieved from file:///C:/ Users/User/Downloads/appraisal\%20for\%20doctors.pdf 
O'Shaughnessy, S. M., \& Joyce, P. (2015). Summative and Formative Assessment in Medicine: The Experience of an Anaesthesia Trainee. International Journal of Higher Education, 4(2), 198-206.

Overeem, K., Faber, M. J., Arah, O. A., Elwyn, G., Lombarts, K. M., Wollersheim, H. C., \& Grol, R. P. (2007). Doctor performance assessment in daily practice: does it help doctors or not? A systematic review. Medical Education, 41(11), 1039-1049.

Sasaki, H., Archer, J., Yonemoto, N., Mori, R., Nishida, T., Kusuda, S., \& Nakayama, T. (2015). Assessing doctors' competencies using multisource feedback: validating a Japanese version of the Sheffield Peer Review Assessment Tool (SPRAT). British Medical Journal Open, 5(6). Retrieved from https://www.ncbi.nlm. nih.gov/pmc/articles/PMC4480000

Sargeant, J., Bruce, D., \& Campbell, C. M. (2013). Practicing Physicians' Needs for Assessment and Feedback as Part of Professional Development. Journal of Continuing Education in the Health Professions, 33(1), 54-62.

Schumacher, D. J., van der Vleuten, C. P. M., \& Carraccio, C. L. (2016). The Future of High-Quality Care Depends on Better Assessment of Physician Performance. Journal of the American Medical Association. Paediatrics, 170(12), 1131-1132.

Stausmire, J. M., Cashen, C. P, Myerholtz, L., \& Buderer, N. (2015). Measuring General Surgery Residents' Communication Skills From the Patient's Perspective Using the Communication Assessment Tool (CAT). Journal of Surgical Education, 72(1), 108-116.

Taveira-Gomes, I., Mota-Cardoso, R., \& Figueiredo-Braga, M. (2016). Communication skills in medical students - An exploratory study before and after clerkships. Porto Biomedical Journal, 1(5), 173-180.

Teter, J., Zenilman, M. E., \& Wachter, P. (2016). Assessment of Endoscope Reprocessing Using Peer-to-Peer Assessment Through a Clinical Community Johns Hopkins Medicine Cleaning, Disinfection and Sterilization Clinical Community. Joint Commission Journal on Quality and Patient Safety, 42(6), 265-270.

Violato, C., \& Lockyer, J. (2006). Self and Peer Assessment of Pediatricians, Psychiatrists and Medicine Specialists: Implications for Self-Directed Learning. Advances in Health Sciences Education, 11(3), 235244. 